https://helda.helsinki.fi

Expect analgesic failure; pursue analgesic success

\author{
Moore, Andrew
}

2013-05-03

Moore , A, Derry , S, Eccleston , C \& Kalso , E 2013, ' Expect analgesic failure; pursue

analgesic success ' , BMJ : British Medical Journal , vol. 346 , no. Article Number: f2690 . https://doi.org/10.1136/bm

http://hdl.handle.net/10138/159378

https://doi.org/10.1136/bmj.f2690

publishedVersion

Downloaded from Helda, University of Helsinki institutional repository.

This is an electronic reprint of the original article.

This reprint may differ from the original in pagination and typographic detail.

Please cite the original version. 


\title{
Expect analgesic failure; pursue analgesic success
} Most analgesic drugs work well but in only a small percentage of people. Andrew Moore and colleagues argue that we need to move away from a focus on average response and seek out what works for each patient

\author{
Andrew Moore professor ${ }^{1}$, Sheena Derry senior research officer ${ }^{1}$, Christopher Eccleston professor ${ }^{2}$, \\ Eija Kalso professor ${ }^{3}$
}

${ }^{1}$ Pain Research and Nuffield Division of Anaesthetics, University of Oxford, Churchill Hospital, Oxford OX3 7LJ, UK; ${ }^{2}$ Centre for Pain Research, University of Bath, Bath, UK; ${ }^{3}$ Pain Clinic, Department of Anaesthesiology, Helsinki University Central Hospital, Finland

\begin{abstract}
A 2003 newspaper article caused considerable grief for the pharmaceutical industry. Entitled, "Our drugs do not work on most patients,"1 it claimed that most drugs worked in only $30-50 \%$ of people. While that surprised journalists and the public, it was not news to professionals, including the then editor of the $B M J .^{2}$

Individual patient responses vary greatly, as a clinical trial of pregabalin in fibromyalgia shows (fig $1 \Downarrow$ ). Pain relief is not normally distributed but usually bimodal, being either very good (above $50 \%$ ) or poor (below 15\%). ${ }^{3-5}$ Using averages is unhelpful and misleading, because "average" pain relief is actually experienced by few (if any) patients, and it tells us nothing about how many patients will experience clinically useful pain relief. Research is therefore moving to responder analyses-reporting the proportion of patients achieving outcomes that patients consider worthwhile.
\end{abstract}

In this article we examine rates of success and failure of drugs used in treating pain. We suggest a radical rethink of achievable analgesic effects, and explore how anticipating and recognising analgesic failure will help improve the management of pain. This approach is relevant to all painful conditions, but here we use examples from acute postoperative pain, headache, and chronic musculoskeletal and neuropathic pain.

\section{Measuring effectiveness}

Patients want large reductions in pain intensity (typically at least $50 \%$, ideally no worse than mild pain ${ }^{6}$ ), with relief from associated problems such as sleep disturbance and depression but without common adverse events interfering with treatment. Those who get better (responders) do well: recent individual patient analyses for chronic pain interventions have shown that people who respond experience improvements in fatigue, depression, and sleep interference, ${ }^{7-9}$ and general measures of function and quality of life, ${ }^{89}$ including ability to work. ${ }^{10}$
Non-responders have none of these benefits. This message is easy to communicate.

An important feature of responder analysis, reflecting clinical practice, is that everyone who withdraws from a trial for any reason is unequivocally a non-responder: if you don't take the tablet you don't get pain relief. This eliminates the need to assign efficacy results to people no longer in trials and eliminates the considerable bias inherent in the statistical practice of imputing missing data. ${ }^{11}$ Imputation methods may be justified in establishing whether interventions have analgesic effects but not when determining clinical effectiveness.

We propose that the scientific assessment of analgesia and the clinical practice of analgesic delivery could be simplified into three guiding principles: measure pain in individual patients, expect analgesic drugs to fail to provide a good response in most patients, and prepare for the next step when failure occurs.

\section{Defining and calculating failure for pain drugs}

The table $\Downarrow$ shows drug specific success and failure rates for postoperative pain, migraine, and chronic musculoskeletal and neuropathic conditions. Data came predominantly from Cochrane reviews or overviews, or individual patient data meta-analyses using sensitive trials in patients with initial pain of moderate or severe intensity. The reviews were done to the highest current standards, ${ }^{12}$ avoiding known risks of bias, and with sufficient data to minimise random chance effects. ${ }^{13}$ All reviews used a responder definition of at least $50 \%$ pain relief or its equivalent. When possible we did not use trials that had imputed data by carrying the last observation forward, but for painful diabetic neuropathy and postherpetic neuralgia, these were the only data available for most drugs. 
The size of response rates with placebo depends on the outcome (lower placebo rates with tougher outcomes), duration (in chronic pain trials), and pain condition studied. We therefore calculated the maximum possible success as $100 \%$-placebo response and drug specific success as active response-placebo response. The success rate was calculated as a percentage of maximum possible response.

\section{Confronting failure}

Drug specific success rates were above $50 \%$ for only four drugs in acute postoperative pain (paracetamol $500 \mathrm{mg}+$ ibuprofen $200 \mathrm{mg}$; paracetamol $1000 \mathrm{mg}+$ oxycodone $10 \mathrm{mg}$; etoricoxib $120 \mathrm{mg}$; ibuprofen $400 \mathrm{mg}+$ codeine $26-60 \mathrm{mg}$ ) and one in migraine (zolmitriptan $10 \mathrm{mg}$ ). For all other drugs and in all other conditions, fewer than half of patients achieved at least a $50 \%$ reduction in pain intensity. In acute postoperative pain, the failure rate was $66 \%$ with paracetamol $1000 \mathrm{mg}$ and $53 \%$ for both ibuprofen $400 \mathrm{mg}$ and diclofenac $50 \mathrm{mg}$. In migraine, failure rates were $55-71 \%$ for most interventions. Failure rates for non-steroidal anti-inflammatory drugs were $58-72 \%$ in ankylosing spondylitis, $\geq 70 \%$ in osteoarthritis, and $\geq 80 \%$ in chronic low back pain. For neuropathic conditions, antidepressants and antiepileptics had failure rates of $\geq 70 \%$ in painful diabetic neuropathy and postherpetic neuralgia, and $\geq 87 \%$ in fibromyalgia. Data for opioids in chronic non-cancer pain were available only for tapentadol and oxycodone in a combined analysis of osteoarthritis and chronic low back pain trials; tapentadol had a failure rate of $90 \%$ and oxycodone had a failure rate of $100 \%$, consistent with what is seen with other analyses for conventional strong opioids. ${ }^{11}$

\section{Reflecting on failure}

The magnitude of the failure to achieve good pain relief, especially over the longer term in chronic pain, is sobering. The high failure rates are a consequence of using patient centred definitions of benefit combining high level of pain relief with tolerable adverse events, using higher standards of evidence, and avoiding major imputation bias. These higher standards are backed by considerable evidence supporting their validity.

Use of responder analysis changes judgments of benefit and risk. With failure, patients without benefit should be exposed to no risk because the drug is stopped; only effective drugs should continue to be prescribed. With success, considerable benefits in terms of pain relief, sleep, fatigue, depression, function, and quality of life are balanced against rare risk of serious harm. Average benefits have no part in these discussions. The good news is that success is often achieved within the first two weeks or so of treatment or not at all, ${ }^{14}{ }^{15}$ and when achieved, tends to last.

Classic clinical trials, providing almost all our evidence in chronic pain, may underestimate efficacy. Fixed dose regimens may exacerbate adverse events and withdrawals, resulting in higher failure rates. An alternative approach is to allow patient directed titration to achieve adequate pain relief with tolerable adverse events; only those with treatment success are then randomised blindly between continuing therapy and placebo. Such trials, known as enriched enrolment randomised withdrawal trials, have lower failure rates. In fibromyalgia, titrating pregabalin to an effective dose resulted in good drug specific pain relief lasting six months in $15 \%$ of the original population of patients; the overall failure rate was only $85 \%$ compared with over $90 \%$ in classic trials. ${ }^{16}$
Drug therapy is rarely the only treatment used in chronic pain, but clinical trials designed for regulatory purposes force us into considering single interventions. Randomised withdrawal trials may reflect the real world more accurately and be a better test, but with only a single example this is speculation.

\section{Pragmatic approach}

The principles of treatment should be to measure pain, expect and recognise analgesic failure, and to react to it, pursuing analgesic success rather than blindly accepting failure. In any condition, the order in which analgesics should be tried is predicated on efficacy and safety, and adjusted for individual patient characteristics.

A pragmatic implication of high failure rates is that populations with pain need access to a broad range of drugs to have a better chance of success (box). The problem is the dearth of data to help devise starting, stopping, and switching rules. Currently, we have no good evidence from clinical trials that switching is successful in pain; we have a single study of limited methodological quality ${ }^{17}$ and a suggestion of differences between closely related tricyclics. ${ }^{18}$ Switching drugs works in other conditions, like depression, where randomised trials show that while drugs used individually benefited fewer than half of patients, the majority benefited when failure was followed by another drug. ${ }^{19} 20$

Guideline developers often restrict treatment options to one or two drugs (such as, the NICE neuropathic pain guideline ${ }^{21}$ ). They consider similar drugs to operate as a class, and so select one as the first or only option despite possibly important differences in pharmacokinetics or drug interactions. Less restrictive guidance, centred on patient-clinician interaction and a large dose of clinical wisdom as well as evidence, may do better; the NICE osteoarthritis guidance comes close. ${ }^{22}$

Regulatory authorities also need to recognise that failure is the norm. European regulators, unlike their US counterparts, have refused to license any drug in fibromyalgia because of inadequate average effect size, ignoring the fact that these drugs work well ( $\geq 50 \%$ reduction in pain intensity) in around $10 \%$ of patients with this difficult to treat condition. New drugs are unlikely to be much better. A change in regulatory attitude is overdue, would be sensible, and will benefit patients.

\section{Clinical trial design}

Chronic pain conditions are complex and associated with considerable comorbidity. Coupled with the intricacies of pain modulation, central nervous system changes, and genetic influences, high failure rates with single interventions are unsurprising. The new game in town is specificity of effect for specific targets, but with only a small percentage of patients benefiting. Randomised withdrawal designs seem promising, ${ }^{23}$ but there are few good examples, and they are not always accepted or understood. New designs are also important for non-drug interventions that produce substantial benefits in few patients, including complementary therapies.

We need to determine how best to use the interventions we have to provide better care for more people at lower cost. Clinical effectiveness trials could be one way forward. ${ }^{24}$ They should inform stopping and switching rules to underpin best practice; outlines of informative pragmatic designs are available, building on examples from other chronic diseases. ${ }^{24}$ 


\section{Practical implications of high failure rates}

- No single drug will treat successfully more than a minority of patients with a painful condition

- Successful pain relief is also likely to improve sleep, depression, fatigue, quality of life, function, and ability to work

- Experience (and some evidence) suggests that failure with one drug does not necessarily mean failure with others, even within a class

- We do not know the best order in which to use drugs, in terms of efficacy, harm, or cost

- Success or failure can be determined within 2-4 weeks, and success, when achieved, tends to be long lasting

- Because success rates are low, a wide range of drugs is needed to do the best for most patients, especially in complex chronic conditions

\section{Conclusion}

Embracing high failure rates is the first step to doing better with what we have. Pronouncing about the importance of failure is rare in science. We believe that pain medicine has now reached a degree of maturity where it can confront its failings. We propose a radical transformation in how we establish analgesic efficacy and harm. Clinically this means expecting analgesic failure, assessing pain, and understanding options for stopping and switching. For the drug industry, regulators, and researchers this means casting aside our slavish reliance on the average, and asking what works for whom in what circumstance, recognising that population improvements in overall effect will require access to numerous treatment options to achieve pain relief for the individual.

Contributors and sources: RAM is chairman of a special interest group on systematic reviews for the International Association of the Study of Pain and a Cochrane editor; SD is a Cochrane editor; CE is coordinating editor of the Pain, Palliative, and Supportive Care Cochrane Review Group; EK is professor of pain medicine at the University of Helsinki. RAM is the guarantor. All data used are from Cochrane or non-Cochrane reviews meeting the same rigorous standards, and where in a few cases evidence is not sufficiently rigorous this is highlighted.

Competing interests: All authors have completed the unified competing interest form at www.icmje.org/coi_disclosure.pdf (available on request from the corresponding author) and declare: no support from any organisation for the submitted work; CE has received consultancy or lecture fees from Reckitt Benkiser, Napp Pharmaceuticals, RAM has been a board member or received consultancy or lecture fees from Reckitt Benkiser, Pfizer, MSD, Eli Lilly, Menarini, and Astellas. EK reports board membership or consultancy for Grünenthal, Pfizer, Janssen-Cilag, and Pharmaleads SAS.

Provenance and peer review: Not commissioned; externally peer reviewed.

1 Connor S. Glaxo chief: our drugs do not work on most patients. Independent $2003 \mathrm{Dec}$ 8. www.independent.co.uk/news/science/glaxo-chief-our-drugs-do-not-work-on-mostpatients-575942.html.

2 Smith R. The drugs don't work. BMJ 2003:327:09.

3 Moore RA, Straube S, Paine J, Derry S, McQuay HJ. Minimum efficacy criteria for comparisons between treatments using individual patient meta-analysis of acute pain trials: examples of etoricoxib, paracetamol, ibuprofen, and ibuprofen/paracetamol combinations after third molar extraction. Pain 2011;152:982-9.

4 Moore RA, Smugar SS, Wang H, Peloso PM, Gammaitoni A. Numbers-needed-to-treat analyses-do timing, dropouts, and outcome matter? Pooled analysis of two randomized, placebo-controlled chronic low back pain trials. Pain 2010;151:592-7.
5 Moore RA, Moore OA, Derry S, Peloso PM, Gammaitoni AR, Wang H. Responder analysis for pain relief and numbers needed to treat in a meta-analysis of etoricoxib osteoarthritis trials: bridging a gap between clinical trials and clinical practice. Ann Rheum Dis 2010;69:374-9.

6 Moore RA, Straube S, Aldington D. Pain measures and cut-offs-" "no worse than mild pain" as a simple, universal outcome. Anaesthesia 2013;68:400-12.

7 Arnold LM, Wang F, Ahl J, Gaynor PJ, Wohlreich MM. Improvement in multiple dimensions of fatigue in patients with fibromyalgia treated with duloxetine: secondary analysis of a randomized, placebo-controlled trial. Arthritis Res Ther 2011;13:R86.

8 Hoffman DL, Sadosky A, Dukes EM, Alvir J. How do changes in pain severity levels correspond to changes in health status and function in patients with painful diabetic peripheral neuropathy? Pain 2010;149:194-201.

9 Moore RA, Straube S, Paine J, Phillips CJ, Derry S, McQuay HJ. Fibromyalgia: Moderate and substantial pain intensity reduction predicts improvement in other outcomes and substantial quality of life gain. Pain 2010;149:360-4.

10 Straube S, Moore RA, Paine J, Derry S, Phillips CJ, Hallier E, et al. Interference with work in fibromyalgia: effect of treatment with pregabalin and relation to pain response. BMC Musculoskelet Disord 2011;12:125.

11 Moore RA, Straube S, Eccleston C, Derry S, Aldington D, Wiffen P, et al. Estimate at your peril: imputation methods for patient withdrawal can bias efficacy outcomes in chronic pain trials using responder analyses. Pain 2012;153:265-8.

12 Moore RA, Eccleston C, Derry S, Wiffen P, Bell RF, Straube S, et al. "Evidence" in chronic pain-establishing best practice in the reporting of systematic reviews. Pain 2010;150:386-9.

13 Moore RA, Gavaghan D, Tramèr MR, Collins SL, McQuay HJ. Size is everything-large amounts of information are needed to overcome random effects in estimating direction and magnitude of treatment effects. Pain 1998;78:209-16.

14 Stacey BR, Barrett JA, Whalen E, Phillips KF, Rowbotham MC. Pregabalin for postherpetic neuralgia: placebo-controlled trial of fixed and flexible dosing regimens on allodynia and time to onset of pain relief. J Pain 2008;9:1006-17.

15 Wang F, Ruberg SJ, Gaynor PJ, Heinloth AN, Arnold LM. Early improvement in pain predicts pain response at endpoint in patients with fibromyalgia. J Pain 2011;12:1088-94

16 Crofford LJ, Mease PJ, Simpson SL, Young JP Jr, Martin SA, Haig GM, et al. Fibromyalgia relapse evaluation and efficacy for durability of meaningful relief (FREEDOM): a 6-month, double-blind, placebo-controlled trial with pregabalin. Pain 2008;136:419-31.

17 Lin HY, Cheng TT, Wang JH, Lee CS, Chen MH, Lei V, et al. Etoricoxib improves pain, function and quality of life: results of a real-world effectiveness trial. Int $J$ Rheum Dis 2010;13:144-50.

18 Watson CP, Vernich L, Chipman M, Reed K. Nortriptyline versus amitriptyline in postherpetic neuralgia: a randomized trial. Neurology 1998;51:1166-71.

19 Kroenke K, West SL, Swindle R, Gilsenan A, Eckert GJ, Dolor R, et al. Similar effectiveness of paroxetine, fluoxetine, and sertraline in primary care: a randomized trial. JAMA 2001;286,2947-55.

20 Simon G. Choosing a first line antidepressant. Equal on average does not mean equal for everyone. JAMA 2001;286:3003-4.

21 National Institute for Health and Clinical Excellence. Neuropathic pain: the pharmacological management of neuropathic pain in adults in non-specialist settings. 2010. www.nice.org. uk/guidance/CG96.

22 National Collaborating Centre for Chronic Conditions. Osteoarthritis: national clinical guideline for care and management in adults. Royal College of Physicians, 2008.

23 McQuay HJ, Derry S, Moore RA, Poulain P, Legout V. Enriched enrolment with randomised withdrawal (EERW): time for a new look at clinical trial design in chronic pain. Pain 2008;135:217-20.

24 Moore RA, Derry S, McQuay HJ, Straube S, Aldington D, Wiffen P, et al. Clinical effectiveness: an approach to clinical trial design more relevant to clinical practice, acknowledging the importance of individual differences. Pain 2010;149:173-6.

Accepted: 2 April 2013

Cite this as: BMJ 2013;346:f2690

(c) BMJ Publishing Group Ltd 2013 


\section{Table}

\section{Table 1 | Success and failure of drug treatment for acute and chronic painful conditions}

\begin{tabular}{|c|c|c|c|c|c|c|c|}
\hline \multirow[b]{2}{*}{ Drug and dose (mg) } & \multicolumn{2}{|c|}{$\%$ with outcome } & \multirow{2}{*}{$\begin{array}{l}\text { Maximum } \\
\text { possible } \\
\text { success } \\
\text { (100-placebo) }\end{array}$} & \multirow{2}{*}{$\begin{array}{l}\text { Success } \\
\text { (active- } \\
\text { placebo) }\end{array}$} & \multirow{2}{*}{$\begin{array}{c}\text { Failure } \\
\text { (maximum- } \\
\text { active) }\end{array}$} & \multicolumn{2}{|c|}{$\begin{array}{c}\text { Treatment specific effects (\% of } \\
\text { maximum) }\end{array}$} \\
\hline & Active & Placebo & & & & Success & Failure \\
\hline
\end{tabular}

Acute pain (single dose postoperative) ${ }^{\mathrm{w} 1}$; outcome: $\geq 50 \%$ maximum pain relief over 6 hours

\begin{tabular}{|c|c|c|c|c|c|c|c|}
\hline Paracetamol 500+ibuprofen 200 & 74 & 10 & 90 & 64 & 26 & 71 & 29 \\
\hline Paracetamol 1000+oxycodone 10 & 68 & 13 & 87 & 55 & 32 & 63 & 37 \\
\hline Etoricoxib 120 & 64 & 11 & 89 & 53 & 36 & 60 & 40 \\
\hline Ibuprofen $400+$ codeine $25.6-60$ & 64 & 18 & 82 & 46 & 36 & 56 & 44 \\
\hline Paracetamol 1000+codeine 60 & 53 & 7 & 93 & 46 & 47 & 49 & 51 \\
\hline Diclofenac 50 & 57 & 19 & 81 & 38 & 43 & 47 & 53 \\
\hline Ibuprofen 400 & 54 & 14 & 86 & 40 & 46 & 47 & 53 \\
\hline Naproxen 500/550 & 52 & 15 & 85 & 37 & 48 & 44 & 56 \\
\hline Paracetamol 1000 & 46 & 18 & 82 & 28 & 54 & 34 & 66 \\
\hline Aspirin 1000 & 43 & 16 & 84 & 27 & 57 & 32 & 68 \\
\hline \multicolumn{8}{|c|}{ Acute migraine headache (single dose) ${ }^{\text {w2-w5}}$; outcome: no worse than mild pain at 2 hours } \\
\hline Zolmitriptan 10 & 68 & 34 & 66 & 34 & 32 & 52 & 48 \\
\hline Rizatriptan 2.5 & 61 & 29 & 71 & 32 & 39 & 45 & 55 \\
\hline Ibuprofen 400 & 57 & 25 & 75 & 32 & 43 & 43 & 57 \\
\hline Sumatriptan 100 & 61 & 32 & 68 & 29 & 39 & 43 & 57 \\
\hline Paracetamol 1000 & 56 & 36 & 64 & 20 & 44 & 31 & 69 \\
\hline Aspirin 1000 & 52 & 32 & 68 & 20 & 48 & 29 & 71 \\
\hline \multicolumn{8}{|c|}{ Osteoarthritis (12 weeks' treatment) ${ }^{6 \text { w6-w8 }}$; outcome: $\geq 50 \%$ pain intensity reduction } \\
\hline Tanezumab 10 & 51 & 31 & 69 & 20 & 49 & 29 & 71 \\
\hline Etoricoxib 60 & 44 & 23 & 77 & 21 & 56 & 27 & 73 \\
\hline Naproxen 1000 & 44 & 23 & 77 & 21 & 56 & 27 & 73 \\
\hline Celecoxib 200 & 39 & 22 & 78 & 17 & 61 & 22 & 78 \\
\hline Topical diclofenac $1.5 \%$ & 60 & 50 & 50 & 10 & 40 & 20 & 80 \\
\hline Ibuprofen 2400 & 39 & 27 & 73 & 12 & 61 & 16 & 84 \\
\hline Duloxetine 60/100 & 40 & 30 & 70 & 10 & 60 & 14 & 86 \\
\hline
\end{tabular}

Ankylosing spondylitis (6 weeks' treatment) ${ }^{\mathrm{w} 9} ; \geq 50 \%$ reduction in BASDI

\begin{tabular}{llllllll}
\hline Etoricoxib 120 & 50 & 14 & 86 & 36 & 50 & 58 \\
\hline Etoricoxib 90 & 46 & 14 & 86 & 32 & 54 & 37 \\
\hline Naproxen 1000 & 38 & 14 & 86 & 24 & 62 & 72 \\
\hline
\end{tabular}

Chronic low back pain ( 12 weeks' treatment $)^{5 \mathrm{w} 6}$; outcome $\geq 50 \%$ pain intensity reduction

\begin{tabular}{llllllll}
\hline Etoricoxib 60 & 47 & 35 & 65 & 12 & 53 & 18 \\
\hline Etoricoxib 90 & 47 & 35 & 65 & 12 & 53 & 18 \\
\hline Duloxetine 60/100 & 39 & 30 & 70 & 9 & 61 & 13 \\
\hline
\end{tabular}

Painful diabetic neuropathy (12 weeks' treatment) ${ }^{\text {w10-w12 }}$; outcome $\geq 50 \%$ pain intensity reduction

\begin{tabular}{|c|c|c|c|c|c|c|c|}
\hline Duloxetine $60 / 100$ & 48 & 26 & 74 & 22 & 52 & 30 & 70 \\
\hline Pregabalin $600^{*}$ & 46 & 30 & 70 & 16 & 54 & 23 & 77 \\
\hline Gabapentin $\geq 1200^{*}$ & 40 & 23 & 77 & 17 & 60 & 22 & 78 \\
\hline Lacosamide $400^{*}$ & 35 & 25 & 75 & 10 & 65 & 13 & 87 \\
\hline Pregabalin $300^{\star}$ & 38 & 29 & 71 & 9 & 62 & 13 & 87 \\
\hline
\end{tabular}

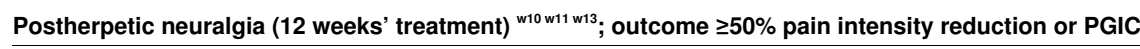

\begin{tabular}{llllllll}
\hline Pregabalin $600^{*}$ & 39 & 14 & 86 & 25 & 61 & 71 & 29 \\
\hline Topical capsaicin $8 \%$ & 39 & 25 & 75 & 14 & 61 & 19 & 70 \\
\hline Pregabalin $300^{*}$ & 30 & 11 & 89 & 19 & 79 & 21 \\
\hline
\end{tabular}


(continued)

\begin{tabular}{|c|c|c|c|c|c|c|c|}
\hline \multirow[b]{2}{*}{ Drug and dose $(\mathrm{mg})$} & \multicolumn{2}{|c|}{$\%$ with outcome } & \multirow{2}{*}{$\begin{array}{c}\text { Maximum } \\
\text { possible } \\
\text { success } \\
\text { (100-placebo) }\end{array}$} & \multirow{2}{*}{$\begin{array}{l}\text { Success } \\
\text { (active- } \\
\text { placebo) }\end{array}$} & \multirow{2}{*}{$\begin{array}{c}\text { Failure } \\
\text { (maximum- } \\
\text { active) }\end{array}$} & \multicolumn{2}{|c|}{$\begin{array}{c}\text { Treatment specific effects (\% of } \\
\text { maximum) }\end{array}$} \\
\hline & Active & Placebo & & & & Success & Failure \\
\hline Gabapentin $\geq 1200^{*}$ & 33 & 20 & 80 & 13 & 67 & 16 & 84 \\
\hline \multicolumn{8}{|c|}{ Fibromyalgia ( 12 weeks' treatment ${ }^{6 \mathrm{w} 14} ;$ outcome $\geq 50 \%$ pain intensity reduction } \\
\hline Duloxetine $60 / 100$ & 28 & 17 & 83 & 11 & 72 & 13 & 87 \\
\hline Pregabalin 600 & 23 & 15 & 85 & 8 & 77 & 9 & 91 \\
\hline Pregabalin 450 & 21 & 15 & 85 & 6 & 79 & 7 & 93 \\
\hline Pregabalin 300 & 19 & 15 & 85 & 4 & 81 & 5 & 95 \\
\hline \multicolumn{8}{|c|}{ Osteoarthritis and chronic low back pain ${ }^{w 15} ;$ outcome $\geq 50 \%$ pain intensity reduction } \\
\hline Tapentadol 200-500 & 30.1 & 23.5 & 76.5 & 6.6 & 69.9 & 9 & 91 \\
\hline Oxycodone 40-100 & 20.8 & 23.5 & 76.5 & -2.7 & 79.2 & 0 & 100 \\
\hline
\end{tabular}

BASDI=Bath Ankylosing Spondylitis Disease Activity Index; PGIC=patient global impression of change.

*Used imputation by last observation carried forward. 


\section{Figure}

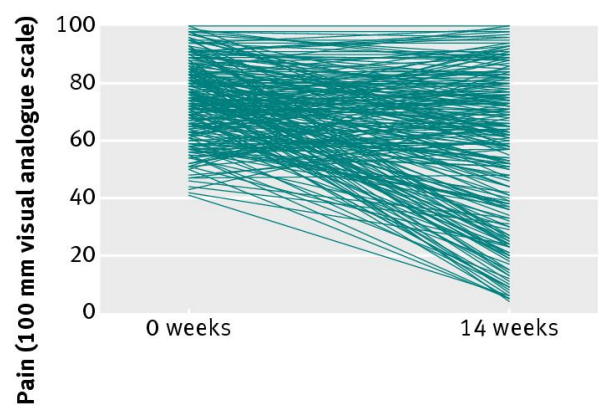

Fig 1 Individual changes in pain over 14 weeks of treatment with pregabalin $450 \mathrm{mg}$ in 200 patients with fibromyalgia 